\title{
Mismatches between Teachers' Expectations and Students' Performances
}

\author{
Elsa Tragant \\ Universitat de Barcelona
}

\begin{abstract}
This paper draws from a larger study that examined the structuring of language lessons (Tragant 1994), that is, how teachers set the stage for activity and how they bring activity to a close. One major observation in that study was that there were times where what the teacher told students to do differed from what some students ended up doing in their groups or individually. The present article intends to present, classify and interpret the instances where that mismatch occurred. The data consists of eighteen transcripts from three undergraduate EFL classrooms at a major university in Spain. The analysis of the data points to three types of mismatches (simplified performances, adapted performances and overworking behaviours) and relates them with a number of aspects of the activity (i.e., the linguistic requirement and the activity-type) and with the instructor's teaching style.
\end{abstract}

\section{Introduction}

When teachers set students to work on language activities in groups or on their own, they are usually concerned with giving clear instructions. This concern comes from the impossibility of the teacher being present when students actually perform the assigned activity. Thus, it is possible that, at times, the process one or more students follow does not match the teacher's expectations. If this happens, it is likely to go unnoticed by the teacher. This paper grows out of an awareness of the importance of the process during individual and group work, as well as out of a worry that some of the students' deviant 
processes may distort the teacher's objectives, thus minimising the usefulness of certain activities. The present study identifies classroom episodes where there is one such mismatch, classifies and describes them in order to further explore why they occur.

\section{Review of the literature}

Students, both in the field of ESL and general education, have been observed to not always carry out activities the way their teachers expect them to. Kumaravadivelu (103) labels this type of mismatch as "strategic" and cites a case where the teacher expects students to do a problem-solving activity through discussion and negotiation, while the transcript of one group of students shows that there is little of that. However, this type of mismatch has not been systematically examined yet.

From the passing references to strategic mismatches in the literature, it is shown that some students have a tendency to simplify activities and make them easier. Hosenfeld (121) describes a case where a foreign language teacher of French thinks students are reading for meaning in doing a grammar exercise. Through a talk-aloud procedure, one of her junior high students reports not to perform the activity the way the teacher anticipates. She is completing the activity with the minimum possible information, that is, without reading for meaning. Similar behaviours are reported from children who modify the activity "in order to eliminate those elements .... designed to improve the quality of the solutions but slow down the process" (Galton and Williamson 89-90). These researchers (50-1) describe a group of pupils in a primary classroom who ignore the teacher's instructions when she tells them first to discuss which pupil should colour in various sections of a map. Instead, pupils proceed immediately to the practical activity, assuming responsibility for the different activities on a first come first served basis. These authors further observe that when the teacher becomes aware of this strategic mismatch, she repeats instructions to slow down the process. The students in turn find the teacher's reaction annoying since it interferes with their objective of completing the activity as soon as possible.

It is important to note that when strategic mismatches like the ones mentioned above occur, they do not necessarily involve all the students in the classroom. Instead, clear individual differences are detected. While some students have been observed to be performing an activity differently from the teacher's expectations, simultaneously other students have been observed to be performing the activity as intended (Bennett and Dunne 88). This variability makes this phenomenon even more appealing to research.

The teacher's instructions play an important role in these mismatches and that is probably why the way teachers open activities is a major concern for most of them, as reflected in several books addressed to the practice of teaching (Parrott 100-105; Richards and Lockhart 113-137; Wajuryb 74-84) as well as in some observational schemes (Fanselow; Rees). As regards the systematic study of teachers' instructions, Gagné and McGrath, Davies and Mulphin are two reference points in this area, drawing from an analysis of second and foreign language lessons respectively. Gagné skilfully distinguishes three functions in the openings of activities (framing the activity, linguistic preparation and psychological preparation) and quantifies the T-S interaction in these openings. McGrath 
et al. also analyse lesson beginnings, and their functions, but include an additional element, which is the students' attitudes towards how their language teachers start lessons. Nevertheless, these two studies have centred on teacher talk and have not looked into the degrees of match or mismatch between what the teacher says in introducing an activity or lesson and how this is interpreted and actually performed by students subsequently. The present study brings these two elements together: it compares the teacher's instructions with the interaction that students generate as they perform an activity in groups or individually.

\section{Introduction to the study}

The data collected for the study were observational and included both field notes (18 visits from October to February) and audio records (18 transcripts from March to May) from three intermediate-level EFL classes visited non-consecutively. These classes were taught at a language school at a major university in Spain and they had an average of 17,11 and 18 undergraduate students each. Each class was taught by a different teacher, Bob, Mark and Sharon, all of whom were native speakers of English and had taught for at least three years at the school.

During the recording of the lessons, two microphones were used: a hand microphone supported by a floor stand to record the teacher and a cordless microphone worn by a student (not always the same student). This second microphone allowed the researcher to capture most of the spontaneous talk from that student and her or his neighbouring classmates in a quite inconspicuous manner. After the recordings, the lessons were transcribed in full and instances where students' individual or group performances differed from the teachers' instructions were identified and analysed inductively. ${ }^{2}$ The result of the analysis is presented in the present paper through description (with frequent excerpts from classroom interaction) and interpretation of the target events.

\section{Three types of mismatches}

Generally speaking students in all three classes followed the teachers' instructions quite faithfully. However, a few occasions could be identified where students' performances in some way differed from the teachers' guidelines or expectations. ${ }^{3}$ These 'deviant' performances could be grouped into three types:

(1) Simplified performances, that is, student modifications that resulted in a simplification (the task was made easier or was carried out quickly);

(2) Adapted performances, which refer to modifications that changed an aspect of the task as it was explained or assumed by the teacher to be performed. These changes, however, did not result in a simplification. They just consisted in doing a task in a different way;

(3) Overworking, which consisted in doing work that had not been requested by the teacher. 
The following sections are devoted to a detailed description of these three types of modifications.

\section{Simplified Performances}

\subsection{Description}

As regards simplification, some students were observed to perform some problem-solving tasks $^{4}$ in quite peculiar ways, ways that the teacher may have discouraged if he or she had been there, or ways that students would not have followed in the teacher's presence. The simplifications consisted in not using the linguistic forms they were supposed to be using at some strategic times, as will be illustrated through the description of three episodes.

In the first episode students had been given three plans (A, B and C) to improve the traffic conditions of a town and Bob told them to, first of all, decide which plan they would choose. Once agreed on that, they were told to write the resolution down. So there were two steps involved. Bob also made clear in his instructions to the students what the grammatical focus of the task was before releasing them to group work,

- excerpt 1 (See Appendix 1 for the transcription conventions)

$\mathrm{T}$ Remember we are using conditionals here. Yeah. This part of the exercise is a conditional exercise.

Interestingly enough, a group of students was observed not to use conditionals in the first step of the task when they were interacting with each other to reach a solution. It was not until they started to reproduce their ideas in writing, the second step, that it crossed their minds that they should be using conditionals (excerpt 2, line 3). Still, however, there was some struggle as to whether to actually use conditionals or not. Two students (L3 and L4) proposed not to (lines 7-8) but L17 (the student in charge of writing) included them (see bold type line 13) and L3 'gave in' (see bold type line 15):

- excerpt 2

(1) L3 We are going to (.04) develop all the plan A. ((Dictating))

L17 ((Writing))

L3 Ah no! Pero seguramente lo querrá con (.02) ¿cómo lo querrá? con should. No con...

L4 Sí, con conditional.

(5) L3 Con conditional, X.

L17 If tal tal tal, I tal tal tal. ¿No?

L3 No. Es muy difícil de hacerlo así.

L4 No. Va ya está bien eso!

LL ((Chuckles))

(10) $(\ldots) \quad((.08$ inaudible $))$ 


\section{L17 Develop?}

L3 Develop, desarrollar. Desarrollar.

L17 Ah desarrollar! Would develop, no? (.04) The plan A. ((Writing for .11)) OK? (.04)

(15) L3 And (.04) we would take the ... the bridge of plan B. ((Dictating)) L17 ((Writing for .07))

What is most interesting is that later use of conditionals continued to be strategic. When Bob approached the group and asked one of these three students about the plan they had chosen, L17 read what they had written and Bob praised the use of the conditional (see line 5).

- excerpt 3

(1) T-G Have you got your plan yet?

G Yes.

T Yeah? Go on imagine I'm another group and explain your plan to me.

L17 =We would develop,

(5) T Good. Sorry.

L17 We would develop all the plan A and we would take the bridge of the plan B to avoid the traffic delays. We would build a north-west bypass to rejoin the A347 west of the plan. ((Reading))

But in the next stage of the task when groups reported to each other in small groups (and the teacher was not monitoring the group), that same student (L17) went back to not using conditionals.

Towards the end of the lesson Bob said to the whole class that students were not doing badly on conditionals. We do not know it students other than L17 followed this pattern of action but it seems clear that L17's performance would not have pleased the teacher, since in various lessons he had explicitly said he was interested in students internalising grammar ('getting comfortable') and using it naturally.

Turning to the second and third episodes, we find a similar type of avoidance when performing another problem-solving task, where students were given three ambiguous pictures and were asked to interpret them by answering multiple choice items (see Appendix 2). Students in groups had to agree on the answers making use of 'must' or 'must have' and give a rationale for the interpretation.

Regarding the second episode, the strategic behaviour of one group of students consisted here in doing the task in two phases. In the first phase students completed the task without using the modals. Instead 'I think' was at times used to express a lack of certainty. This can be observed in excerpt 4 where students were chosing the answer to question one picture three and reasoned it out without using any modal verb.

- excerpt 4

(1) L11 At the hotel. 
L10 I think he is at the hotel.

L11 At home, no?

L10 At the hotel I think.

(5) L11 At the hotel?

L10 Because $[\mathrm{XX}=$

L12 [The hotel I think, no?

L11 Why?

$\mathrm{L} 10=$ Is fire cartel.

(10) L12 Yes.

L10 Instructions.

L11 Ah, yes. Yes.

L12 And he has the case under the ... =

Lll Mm.

(15) $\mathrm{L} 12$ =the bed.

L10 The case under under the bed, aha.

Excerpt 5 belongs to the second phase, after students had quickly decided on their answers to the three questions in picture three. One student in the group proposed going on to another picture (they had not yet talked about pictures one or two). But another student reminded them that they should have used 'must' in talking about picture three. The others in the group agreed readily and they started over with the questions from picture three again, this time using the modal verb in their answers and talking about whether 'must' or 'must have' needed to be used and why. Excerpt 5 reproduces the students' talk when answering question one picture three.

- excerpt 5

(1) L12 He must be [. . at a hotel.

L11 [He must be at at at hotel. Yes.

L11 He must been, no?

L12 No, no, [no.

(5) L11 [No condition. He must have been?

L12 No. [Because it's the past.

L11 [No.

L11 Ah.

L12 When it's present is must be.

(10) L11 OK. Must be.

L12 Must be.

L11 Mm.

The way students went about performing the tasks in episodes one and two was characterised by a fragmentation of form and meaning. When students were dealing with meaning they seemed to forget, ignore or postpone the linguistic requirement embedded in the task. As to the third episode, a similar fragmentation of form and meaning occurred during the performance of the same problem-solving task as in episode two when the same students were assigned to do picture two, question three in the same handout (see Appendix 2). This time, however, the fragmentation first occurred in consecutive turns, 
this being a more subtle type of fragmentation. In one turn a student gave the interpretation of the picture without 'must'. And on a following turn that same student or another gave the corresponding form with 'must' or 'must have,' sometimes repeating the content of what the previous student had said (lines 3 and 12-13), sometimes just giving the verb form in isolation (see lines 18-19). This happened three times in the following excerpt:

- excerpt 6

(1) L11 Putting on, no? (.02) Putting on, no?

L12 I think yes.

L11 She must putting on ... her coat (...)

(...)

(5) L11 This is the waiter. This is the woman and this is his ... eh the man.

L12 Do you think-?

L11 Yeah.

L12 Must be.

L11 Yeah, she must be. Yes.

(10) (..)

L10 A couple and a waiter.

L12 They must be [a couple and a waiter.

L10 [They must be a couple and a waiter.

It will be observed that in the excerpt above students were not giving reasons for their interpretations, in spite of Bob having told this precise group of students to do so some minutes before:

- excerpt 7

$\mathrm{T}$ Make sure you give reasons. That's what's that's really important there. OK? ((T leaves the group)).

As a result, this group of students finished very quickly. When they were going to start to answer another question (excerpt 8, lines 1-2) (which they had not been assigned), one student in the group (L10) slowed them down and made them go back to question three (see lines 4,6 and 8), something very similar to what had happened in episodes one and two. L10 reminded students that Bob had only assigned them to solve one item (question three) and very subtly signalled them that they needed to give reasons (see bold type).

- excerpt 8

(1) L12 Is the man on the right sitting down, getting up to greet them? ((Reading)) What's the meaning of greet?

L10 No, number three. Number three!

(5) L12 Only number three!

L10 Number three and [picture two number three.

L12 [Ah.

L10 Only number three. 
L12 [Ah.

(10) L10 [I think I think is is [. . putting on the coat. (Sí claro) ((Self talk))

L12 [(Excuse me) XXX

L11 Putting.

L10 Because $=$

L11 = Yes because eh if she must take- she must (.02).

(15) L10 The the paper who have this man must be the the bill.

L12 (But) if this paper is the bill eh they must (.02) no [they must be going out.

(...) ((The discussion in the group continues with thirteen turns))

Only when this group was done with giving reasons, did L10 signal that they could go on to another multiple choice item.

- excerpt 9

L10 Ja està.

L12 And the second, do you know what's $X$ greet?

In this last episode, even if students dealt with meaning and form at the same time (although in separate turns), they did not answer the questions in full in the first phase of their performance. Students used a second round to do so. So once again we get evidence that students were not doing the assigned problem-solving task as spontaneously as the teacher would have liked.

\subsection{Interpretation}

A common trait of the three episodes illustrating simplification is that at some point there was a student who readdressed the task and students ended up doing the task in the teacher's way sooner or later-they ended up with the expected product. However, on several other occasions in the data the student who did this 'monitoring' was unfortunately not always there.

A more general trait is that students were dealing with content and form separately or intermittently. In episodes one and two, only when students had decided what they were going to say, did they pay attention to how they were going to say it. In episode three, students dealt with content and form simultaneously but they only dealt with part of the content then. In a second phase they would deal with the rest of the content. What is interesting is that in this fragmentation of content and form, the 'rehearsal' that first took place was never displayed to the teacher, who always heard the final draft including the target linguistic items. At first sight, this intermittent orientation to skill/content and form seems to contradict the purpose of communicative tasks, which are intended to integrate meaning and form (Nunan, The Learner-centered Curriculum), especially in cases when students used the $\mathrm{L} 1$ to deal with meaning first. This phenomenon could hypothetically be traced back to causes related to cognitive processes as well as to a strategic behaviour on the part of the students. 
In the light of psycholinguistics, maybe this dealing with form and content separately is a characteristic of the stage of these students' learning development and consequently should and could not be avoided. Our transcripts bear a certain resemblance to those of children acquiring a second language, where a child gradually builds up his utterances as Hatch $(409,411)$ reports:

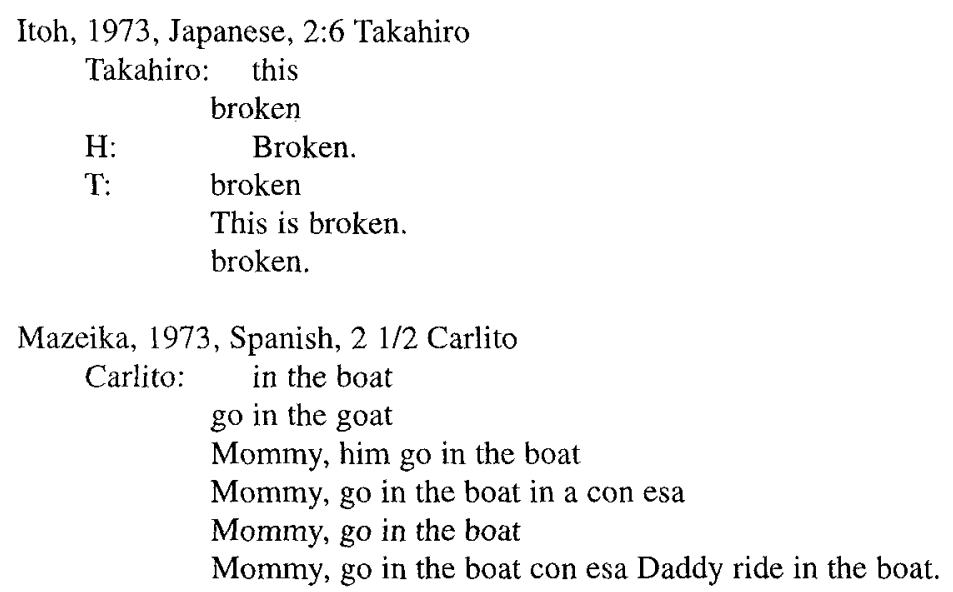

Students' tendency to deal with content and form at different times could in part be attributed to the students' limited capacity to pay conscious attention to form and at the same time process output for meaning. There is evidence from the literature on reading (VanPatten) and process writing (e.g., White and Arndt) that this limited processing capacity causes students to fragment content and form. In a way, what the students in the quoted excerpts did was a kind of drafting in the first phase of their work in groups (sometimes in the L1 and sometimes in the L2 and always orally), the second phase being a kind of revised version or final draft (always in the L2 and sometimes in writing).

A second factor that may explain the divorce of content from form may be found in two types of strategic behaviours on the part of the students: a tendency to do the minimum work possible and an eagerness to be ready when the teacher approached the group. It is possible that some of the students had a tendency to solve problems or go through activities quickly, making them as easy and straightforward as possible (recall the student in excerpt 1 who proposed not including an assigned linguistic focus on the basis that: "Es muy difícil hacerlo asî" ("It is very difficult to do it like this"). It somehow gives the impression that some of these students may have seen their work in groups away from the teacher as purely a preparation for the time when they would perform in front of him or her and not as an objective in itself. That would explain why, at times, students did not integrate content and form in the absence of the teacher, but would do so in his or her presence.

Another interpretation of why students simplified tasks during group work could have to do with a concern with time on the part of the students. Maybe students sectioned tasks into two phases as a strategy to make sure they would be 'ready' in case the teacher 
approached their group. That is, so that when he or she came around, students would 'have' the answers. Only after this preliminary phase would they be able to go back and restart without a concern for time.

\section{Adapted Performances}

\subsection{Description}

We will now turn to the second type of modification, adaptation. Here we find times when individual students adapt an activity and times when students publicly cause the teacher to announce an official adaptation. In instances of the first case, the students a priori decided to do the activity differently from how it had been assigned without the teacher's permission. On one occasion, Sharon had told her students to talk about their best friend but two students were observed writing (not speaking) about their oldest friend (not the best friend). The topic shift was negotiated overtly between the two students:

- excerpt 10

L6 I don't have a: a best friend.

L7 Yes. (.06) I have few fewest friends. My oldest friend,

L6 Yes.

L7 I want to talk about my oldest friend.

L6 ((Chuckles))

There is a similar instance in the data where Mark explicitly told students to write notes as they were preparing a role-play and a pair of students were observed not to do the writing but to go directly on to the speaking part. None of the three teachers, however, was ever worried about the adaptations identified in the data, although it is unclear to what extent teachers were aware of them. In the activity about 'best friends' (see excerpt 10) Sharon was actually told about the change of topic (from best friends to old friends) and she showed approval.

We will now move on to the occasions when one or more students intended to elicit an official modification, that is, a public announcement by the teacher allowing students to perform an activity somewhat differently from the way it had initially been presented. What is most curious about these incidents is that students made such requests in a covert manner. In the cases identified in the data students always made this request disguised as a clarification question, as if something about the instructions of the activity was unclear, when the actual purpose of the question seemed to be to seek permission from the teacher to adapt the activity. In excerpt 11, after Mark had directed his students to choose an adjective from a list in the textbook in order to write questions, there was an attempt to get approval to write questions using adjectives from outside the list in the textbook. Such an attempt was not direct, but started with L9's clarification request in line 1, followed by Mark's repetition of instructions in lines 2 and 4, and a choral display of lack of enthusiasm in line 5, which finally caused Mark to give in and announce the adaptation in line 6. 
- excerpt 11

(1) L9-T ((Asks if they have to choose an adjective from the book))

T-L9 No, choose an adjective from the book.

L9-L10 From the book.

T-C Yes. Choose, I mean, choose an adjective from this list, sorry, [XX.

(5) C [Ah. O::h.

T-C OK. Choose another adjective. If you want to choose another adjective you can.

Similar instances that follow the same pattern are found in the data: first one or more students' clarification request, then the teacher's repetition of instructions, followed by a display of lack of enthusiasm. The teachers' reactions varied, though, sometimes allowing the adaptation of the activity sometimes not.

\subsection{Interpretation}

When contrasting the two types of adaptations drawn from the data, it is interesting to observe the differences in the students' behaviours. In the first type the students felt free to perform the assigned activity differently and in the second type they seemed to need the teacher's permission. It is difficult to tell from the data what led students to behave in one way or another, although variables like the student, the type of activity or the teacher probably have something to do with it.

These two types of adapted performances have one thing in common though, the students' adaptations or requests for adaptation never implied a simplification of the activity, they were just attempts to perform the assigned activity differently, either with a variation of the topic or the procedure or both. This phenomenon may lead us to think that some of the activities initiated by the teachers were felt to be too restrictive by some students, this restriction apparently being what triggered the adapted performances or the attempts to adapt them.

\section{Overworking In Performances}

\subsection{Description}

The third and last type of modification, overworking, was a behaviour only noticed in Mark's class, and it consisted of certain individuals' habit of copying on occasions where Mark had not asked his students to do so and on occasions where it seemed not to be necessary. For example, some students were observed to write full sentences in carrying out a grammar exercise where the teacher had modelled only writing the verb forms. On another occasion, students were asked to underline a number of verb forms directly in the textbook and three students were observed to copy the text in their notebooks, thus taking a longer procedure than that suggested by Mark. Additionally, students in this class were once seen copying down the instructions to perform an activity that Mark wrote on the blackboard. Three out of six students that were being closely observed copied the set of 
instructions down from the blackboard while the teacher was writing them, something that Mark had not requested and made little sense to copy.

\subsection{Interpretation}

Even though the illustrations of overworking were instances of student behaviours not ordered by the teacher, Mark could have encouraged that behaviour indirectly because on occasions he himself was observed to do or expect his students to do unnecessary work. For example, Mark often used to write on the blackboard to provide the answers to activities, to explain grammar, to write phonetic transcriptions, to give procedural information and to write exercises for students to do on the spot, something that neither Bob nor Sharon did with such frequency. In comparison with the other two teachers his uses of the blackboard were not only frequent, but also relatively long ${ }^{5}$ and not very interactive, since at these times Mark had the habit of turning his back to the students without announcing what it was that he would be writing. In addition, Mark often used to expect students to copy what he had written and also left considerable time for students to do so, making the procedure longer. In sum, some of what he wrote on the blackboard and expected students to copy was not strictly necessary and that could have facilitated the described overworking behaviours. Some students may have automatically written everything Mark wrote without making the effort of discriminating what was worth taking note of from what was not. Or they could have adopted that behaviour out of an eagerness to keep engaged, to do something at these times where the teacher left students with nothing to do.

\section{Summary and Implications}

In this paper we have looked at classroom events where the three teachers seemed to have been good at communicating to students what to do to carry out activities. But in spite of that, some students at times did not carry them out as the teacher initially expected. The instances of mismatches could be classified into three (simplification, adaptation and overworking), some mismatches occurring with certain types of activities (simplifications occurred with problem-solving tasks and overworking with individual work). In simplification, students showed awareness of what to say in the first minutes of the performance stage and then they showed awareness of how to say it or vice versa, but not at the same time. In adaptation, students were observed to, on their own initiative, slightly change an aspect of an activity from how the teacher had explained it at its start, or to seek the teacher's permission for a change masked with a clarification request. Finally, in overworking, students were observed to copy from the textbook, the blackboard or handouts excessively.

Even though the three types of modifications come from a case study and consequently a very specific situation, they can be a point of departure for reflection by any practising second or foreign language teacher. In the first place, an awareness of the phenomenon of simplification may help teachers detect it in their classrooms so that they can take some 
action to minimise it. For example, students may be made aware of the mismatches by evaluating their own performances ${ }^{6}$ or the teacher can explain to them why simplifications can hinder their learning. Secondly, the descriptions of adapted performances give some food for thought as to whether teachers should be careful to plan activities that leave enough freedom for students to decide what to talk or write about (i.e., the topic) and how to go about doing that (i.e., the procedure), since the data in this study seemed to show some students felt some activities to be too restrictive. The third type of modification, overworking, raises the issue of how the teacher's management style may exert a negative influence on how some students carry out some activities, since this is what seemed to occur in our data. Finally, it should be added that if the present study had drawn on more data (more lessons, more teachers, different contexts, or levels of English proficiency), the number of mismatches would probably have been more than three. However, the role of this paper has been not so much to come up with generalisations, but to be a contribution towards the understanding of the nature of the mismatch between learning and teaching. Recently, in an article where Nunan ("Closing the gap between learning and instruction") acknowledges the gap that exists between learning and instruction, he points out that there will always be a certain mismatch. Nevertheless, it is the teacher's job to try to find ways to narrow it. The present paper has been an attempt to make this job easier, more understandable and interesting for the teacher.

\section{Notes}

1. I would like to thank Dr. Ramon Ribé i Queralt for his guidance in the course of this study and Kate Kiss for her comments on this article.

2. The cases where students' deviant performances were caused by unclear instructions on the part of the teacher or by a faulty interpretation of instructions on the part of the students have been excluded from the analysis.

3. Since the purpose of the study is not to quantify the instances of strategic mismatches but to identify types of mismatches, the number of identified instances is not presented.

4. The term 'task' is being used in a more specific way than the term 'activity' to refer to the development of communicative ability in a specific area of the language being taught (Ribé \& Vidal 3).

5. Once, Mark spent five minutes and forty-seven seconds writing an exercise on the blackboard without telling students what it was about. Another day he took a total of three minutes thirty-eight seconds to write a grammar explanation. Numerous other examples are to be found in the data where students were just supposed to wait for Mark to finish his work on the blackboard.

6. I would like to thank Leni Dam for making this suggestion. 


\section{Works Cited}

Bennet, N. and E. Dunne. Managing Classroom Groups. Herts: Simon and Schuster Education, 1992.

Doff, A., C. Jones and K. Mitchell. Meaning into Words (Upper-intermediate). Cambridge: Cambridge University Press, 1984.

Fanselow, J. Breaking Rules: Generating and Exploring Alternatives in Language Teaching. New York: Longman, 1987.

Gagné, F. La Phase Préparatoire des Activités Didactiques en Classe de Langue Seconde: Éttude Descriptive et Exploratoire. Unpublished master's thesis, Université du Québec, Montréal, 1992.

Galton, M. and J. Williamson. Group Work in the Primary Classroom. London: Routledge, 1992. Hatch, E. "Discourse analysis and second language acquisition." In Hatch E. (ed.), Second Language Acquisition. A Book of Readings. Cambridge: Newbury, 1976. 400-435 .

Hosenfeld, C. "Learning about learning: discovering our students' strategies." Foreign Language Annals 9 (1976): 117-129.

Kumaravadivelu, B. "Language-learning tasks: teacher intention and learner interpretation." ELT Journal 45.2 (1991): 98-107.

Mcgrath, I., S. Davies, and H. Mulphin. "Lesson beginnings." EWPAL 3 (1992): 92-108.

Nunan, D. The Learner-centered Curriculum. Cambridge: Cambridge University Press, 1988. 158. "Closing the gap between learning and instruction." TESOL Quarterly 29.1 (1995):133-

Parrott, M. Tasks for Language Teachers. Cambridge: Cambridge University Press, 1993.

Rees, A. "Segmenting classroom activities for research purposes." In Edge, J. and Richards, K. (eds.), Teachers Develop Teachers Research: Papers on Classroom Research and Teachers Developmen. Oxford: Heinemannt, 1993. 54-64.

Ribé, Ramon. and Núria Vidal. Project Work: Step by Step. Oxford: Heinemann, 1993.

Richards, Jack C. and C. Lockhart. Reflective Teaching in Second Language Classrooms. Cambridge: Cambridge University Press, 1994.

Tragant, Elsa. The Structuring of Language-learning Tasks. Unpublished doctoral dissertation, Universitat de Barcelona, Spain, 1994.

Vanpatten, B. "Attending to form and content in the input: an experiment in the consciousness." SSLA 12 (1990). 287-301.

Wajuryb, R. Classroom Observation Tasks. Cambridge: Cambridge University Press, 1992.

White, R. and Arndt, V. Process Writing. London: Longman, 1991. 


\section{Appendix 1: Symbols Used in Transcription}

- Symbols to identify participants:

T Teacher

L1, L2, etc. Identified learner

LL Several learners, three or more.

$\mathrm{G} \quad$ A group of students.

T-L1/T-G Teacher talking to individual students or a small group of students.

C All or most of the participants in whole class configuration.

- Symbols for relationships between speakers' utterances:

$=\quad$ a) A turn continuing below, at the identical symbol.

b) Indicating that there is no gap at all between the two turns, if inserted at the end of one speaker's turn and the beginning of the next speaker's adjacent turn.

[ Overlapping or simultaneous talk.

[

- Symbols used in text:

$(())$

Non-verbal and paralinguistic information of the utterance that precedes the brackets. (...) Stretches of talk, a turn or part of it that have not been transcribed.

I don't- I can't express An unfinished word or utterance, a self-editing marker. (Let me think) ((Self-talk))

Used to indicate that the preceding single bracketed utteranceis not primarily addressed to an interlocutor.

- Symbols for uncertain transcription and silence:

... One second-pause.

(.05) A pause of more than one second. Used to indicate pauses within and in between utterances and turns.

$\mathrm{X}$ Incomprehensible item, probably one word.

XX Incomprehensible item of phrase length.

XXX Incomprehensible item beyond phrase length.

(from the) Uncertain transcription. 
Appendix 2: Handout

(Doff, Jones and Mitchel 65).

\subsection{WHAT'S GOING ON? Practice}

Look at the pictures below, and answer the questions, giving reasons for your deductions.

Picture I

I Do you think they are:
a) friends?
b) strangers?
c) father and daughter?

2 Are they:

a) in the street?

b) in a park?

c) in the garden?

3 Which is true?

a) He's just caught sight of her.

b) They've just had an argument.

c) They're having a walk together.
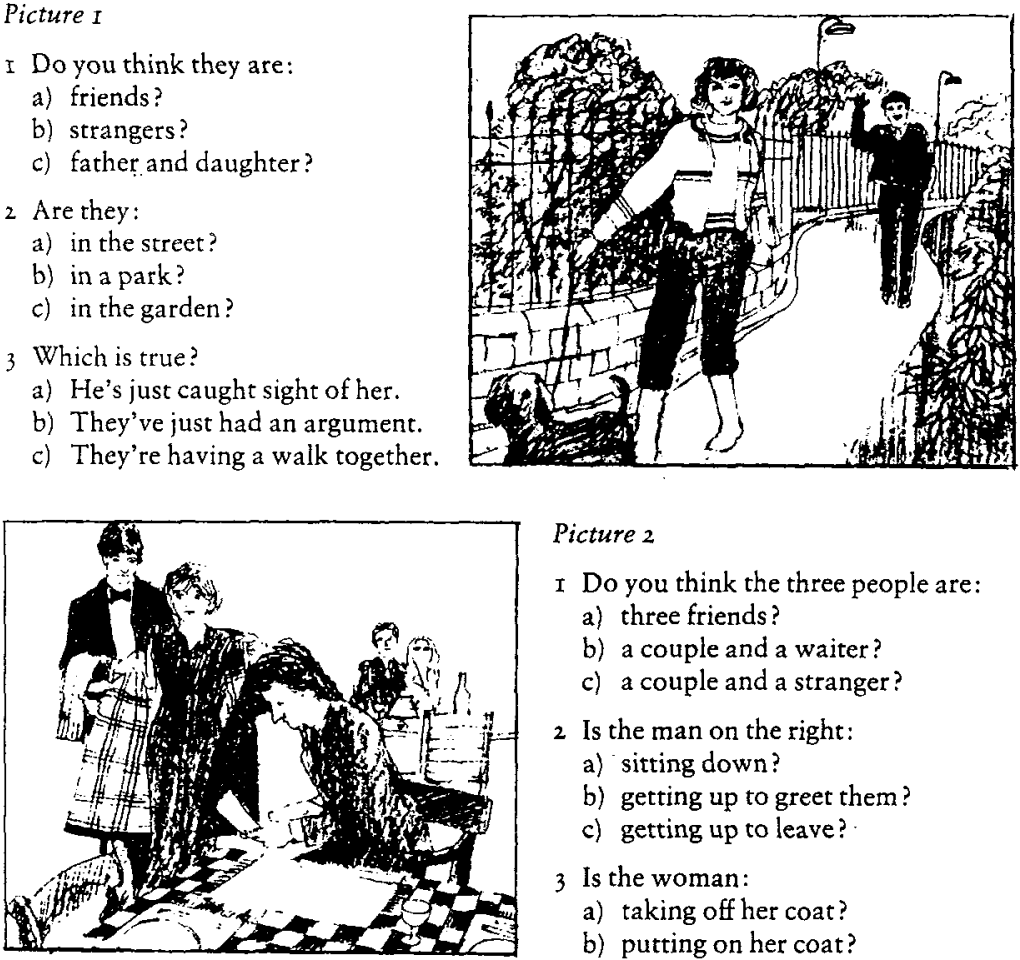

Picture 2

I Do you think the three people are:

a) three friends?

b) a couple and a waiter?

c) a couple and a stranger?

2 Is the man on the right:
a) sitting down?
b) getting up to greet them?
c) getting up to leave?

3 Is the woman:

a) taking off her coat?

b) putting on her coat?

Picture 3

I Do you think he is:
a) at home?
b) at a friend's house?
c) at a hotel?

2 When the phone rang, do you think he was:
a) getting ready for bed?
b) asleep?
c) getting up?

3 Is he:
a) picking up the phone?
b) putting down the phone?

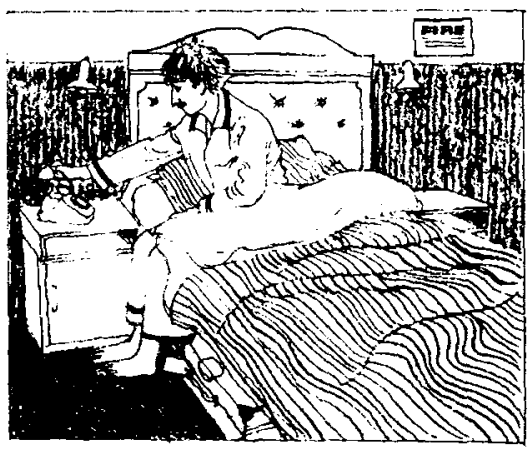

